\title{
Optimal control of the electrical mode of an arc furnace on the basis of the three-dimensional vector of phase currents
}

\author{
Lozynskyi O., Lozynskyi A., Paranchuk Y., Biletskyi Y. \\ Lviv Polytechnic National University, \\ 12 S. Bandera Str., 79013, Lviv, Ukraine
}

(Received 1 March 2019; Accepted 15 April 2019)

\begin{abstract}
In the paper, based on the Fokker-Planck-Kolmogorov equation and the statistical control theory, a mathematical model for the operative synthesis of optimal controlling influences for stabilization of the electric mode of an electric arc furnace in a two-contour structure with a high-speed electric circuit for regulating the arc currents is suggested.

Keywords: arc furnace, electric mode, three-dimensional vector of phase currents, stochastic control, delta function, dispersion, optimization, adaptation.
\end{abstract}

2000 MSC: $93 \mathrm{E} 20$

UDC: $681.513,621.365,62-83-52$

DOI: $10.23939 / \mathrm{mmc} 2019.01 .069$

\section{Introduction}

Electric arc furnaces (EAFs) belong to complicated electrotechnical installations with random nature of the load in the space of three-phase arcs and the power circuit of their supply. This feature complicates the processes of control of such objects and imposes restrictions on systems engineering, e.g. models, methods, and approaches for improving the existing modes of control systems and for the regulation of electric coordinates. At the same time, the problem of complex enhancement of the indicators of electrotechnical efficiency and electromagnetic compatibility of the modes of EAF and an electrical grid is a basis for enhancement of the competitiveness of electric steels and high alloys in the domestic and foreign markets of metal products.

It is obvious that for such electrotechnical nonlinear stochastic objects of control, it is expedient to use models based on probabilistic coordinate characteristics that most fully correspond to the nature of the processes, which occur in such objects.

At present, the control of modes in the vast majority of arc steel smelting furnaces is realized on the basis of classical deterministic models of identification of state, parameters, phase adjustment of coordinates, and control of modes that do not correspond to the stochastic nature of the processes governing their functioning and do not provide the required electrical energy indices.

In order to solve the problem outlined above, in our opinion, it is expedient to improve the existing and create new effective methods and approaches for the control, in particular, the operative formation of the controlling influences based on the three-dimensional vector of phase currents and its probabilistic characteristics.

\section{Mathematical model}

The main objective of this study is to develop a mathematical model for operative synthesis of the electric control signal of an electric arc furnace on a base of three-dimensional vector of the arc currents, which corresponds to the nature of the processes in the object and is of a low sensitivity to the change of parameters; the use of this model in comparison with known solutions enables us to increase the dynamic accuracy of the stabilization of the arc currents at given levels. The practical implementation of this developed model requires the creation of an appropriate algorithm, which will perform the 
adaptive optimal control of the electric mode of an arc steel smelting furnace according to the criterion for minimizing the dispersion of the distribution of the three-dimensional vector of phase currents.

The dynamics of the regulation of the coordinates of the electric mode of the ASF, in particular of the arc currents, in the vast majority of existing (serial, standard) control systems of the process of electro-steelmaking (arc strength) do not fully meet the high modern requirements for energy efficiency and electromagnetic performance of the arc furnace and the electrical grid. Therefore, solving the problem of the creation of the effective control systems that provide an increase in the rate of the processes of regulation of phase currents (arcs) and, on this basis, fully improve the indicators of energy efficiency and electromagnetic compatibility of the modes, is important and relevant for the current electrometallurgical industry.

For the first time, the theoretical basis for the formation of controlling influence for the electromechanical system of displacement of electrodes of the three-phase EAFs based on probabilistic characteristics is given in [1]. The coefficients of the relationship between the half-period average currents of the arcs included in the created model of EAF are suggested to be determined on the basis of the probabilistic analysis and the correlation of the processes in the furnace space. The method of controlling the electric mode of EAF obtained in this paper has made it possible to correct the control signals of typical electric current regulators and, thereby, avoid the false triggers of the regulator of the $i$-th phase (eliminate the false displacements of the electrodes) due to perturbation in the neighbor phases. By means of this method of control, the phase autonomy of the control of the electric mode is achieved, which, in turn, improves the capacity of EAF.

Similarly, the task of the phase autonomy of controlling the electric mode according to the phases of EAF on the basis of taking into account the stochastic parameters of perturbations of neighbor phases is considered in the work [2]. According to this work, the signal that controls the displacement of an electrode in each phase is additively composed of the signals of mismatch of all three phases, which are normalized by the coefficients of the weight. To obtain the values of these coefficients, a mathematical model is suggested describing the reactions of such a complex object as an EAF on the pre-synthesized controlling influences and on the perturbation processes which put the electric modes of a furnace into one or another state. In the end, these coefficients are also some coefficients of the weight of mismatch of phases. Nevertheless, it should be emphasized here that in this paper it is noted that optimization of the system of regulation of the electric mode of an EAF should be conducted with an orientation to such an integrated characteristic of the mode as the dispersion of the three-dimensional vector of currents of the arcs but specific solutions in this direction have not been proposed.

The mathematical and computer models of control systems of electric arc furnaces operation modes suggested in [3-7] have some advantages and disadvantages, which are determined by the completeness and accuracy of the description of electric modes, by the complexity and precision of state identification, and by the conveniences in use and adjustment. The results obtained in these works demonstrate a slight improvement in energy efficiency and electromagnetic compatibility, firstly due to the use in the synthesis of controlling influences of the models that with a not high accuracy describe the nature of the real processes of changing the coordinates of the electric mode, as well as due to the high level of sensitivity of the indicators of the quality of the dynamics to the change of the parameters of an object to be controlled, which is extremely undesirable under the conditions of non-stationary parametric continuous disturbances in the furnace power circuit and in the phase arc intervals.

Let us consider the problem of creating a mathematical model of the formation of controlling influences by the phase channels of the regulation of the electric mode of an EAF on the basis of the distribution density of the three-dimensional vector of phase currents $I=\left(y_{1}, y_{2}, y_{3}\right)$. We assume that the density of the three-dimensional vector of phase currents is ruled by the distribution law in terms of density

$$
p\left(y_{1}, y_{2}, y_{3}\right)=\frac{1}{(2 \pi)^{3 / 2} \sqrt{\operatorname{det} \Lambda_{y}}} \cdot \exp \left[-\frac{1}{2} \cdot \sum_{i, j=1}^{3} \Lambda_{y_{i, j}}^{-1} \cdot\left(y_{i}-\bar{y}_{i}\right) \cdot\left(y_{j}-\bar{y}_{j}\right)\right]
$$

$\Lambda_{y_{i, j}}^{-1}=\frac{1}{\operatorname{det} \Lambda_{y}} \cdot A_{i, j}$ are the elements of the inverse correlation matrix $\Lambda_{y}^{-1}$.

Mathematical Modeling and Computing, Vol.6, No. 1, pp.69-76 (2019) 
To synthesize the vector of controlling influences of the three phases of an arc furnace, we apply the principle according to which the optimal change in the distribution density of the three-dimensional vector of the arc currents is made, which approximates this distribution to the distribution with a minimal dispersion of the three-dimensional vector.

Ideally, if the system performs its purpose better, the sooner it converts the initial distribution density $p\left(y_{1}, y_{2}, y_{3}, t_{0}\right)$ of the three-dimensional coordinate vector of the object into a normal distribution with a minimized dispersion of the three-dimensional vector, the mathematical expectation of which coincides with the point $\left(y_{i}\right)=y_{i \text {.set }}$, where $i=1,2,3 ; y_{i \text {.set }}$ are the given averaged values of the components of the three-dimensional vector of the regulated coordinates of the control object.

This conclusion follows from the assertions of the statistical theory of transient processes, according to which, on the basis of the Fokker-Planck-Kolmogorov equation [8], an optimal control concerning the transient process of changing the density of the $n$-dimensional distribution of probabilities to the normal density with the minimal dispersion of the three-dimensional vector is obtained.

For our case, we write the Fokker-Planck-Kolmogorov equation in the form

$$
\frac{d p}{d t}=\sum_{i=1}^{3} \frac{d\left(p \cdot F_{i}\right)}{d y_{i}}
$$

as an equation for a system in the absence of noise of dataware devices. In Eq. (2) $p$ is the distribution density of the probability of the three-dimensional vector $p=p\left(y_{1}, y_{2}, y_{3}\right) ; y_{i}+F_{i}\left(y_{1}, y_{2}, y_{3}\right)=0$ is an equation describing the motion of the coordinates of the system.

For the system of automatic control, the functions $F_{i}$ can be represented as a set of two functions [8]:

$$
F_{i}=f_{i}\left(y_{1}, y_{2}, y_{3}\right)-u\left(y_{1}, y_{2}, y_{3}\right),
$$

where the functions $f_{i}$ belong to the control object and are called its characteristics and the functions $u_{i}$ refer to the control system and are called controlling influences.

Being synthesized in [8], the control for dynamic systems that provide an optimal change in the distribution density of an $n$-dimensional vector of regulated coordinates $y_{i}$ are calculated as follows:

$$
u_{i}=d_{i} \cdot \operatorname{sign}\left(\frac{\partial \ln (p)}{\partial y_{i}}\right),
$$

here $d_{i}$ is the maximal allowable value of the controlling influence; $y_{i}$ is the component of the vector of the regulated coordinates.

Such a control with respect to one of the coordinates, for example, with respect to the first one, for our case, will be written as:

$$
u_{1}=d_{1} \cdot \operatorname{sign}\left(\frac{\partial \ln \left(p\left(y_{1}, y_{2}, y_{3}\right)\right)}{\partial y_{1}}\right) .
$$

To find the appropriate control, we write the distribution density (1) of the three-dimensional vector of the regulated coordinate of the electric mode of an EAF in a convenient for differentiation form:

$$
\begin{aligned}
& p\left(y_{1}, y_{2}, y_{3}\right)=\frac{1}{(2 \pi)^{3 / 2} \sqrt{\operatorname{det} \Lambda_{y}}} \cdot \exp \left[-\frac{1}{2} \cdot \frac{1}{\operatorname{det} \Lambda_{y}} \cdot\left\{A_{11}\left(y_{1}-\bar{y}_{1}\right)^{2}+2 \cdot A_{12}\left(y_{1}-\bar{y}_{1}\right) \cdot\left(y_{2}-\bar{y}_{2}\right)\right.\right. \\
& \left.\left.+2 \cdot A_{13}\left(y_{1}-\bar{y}_{1}\right) \cdot\left(y_{3}-\bar{y}_{3}\right)+A_{22}\left(y_{2}-\bar{y}_{2}\right)^{2}+2 \cdot A_{32}\left(y_{2}-\bar{y}_{2}\right) \cdot\left(y_{3}-\bar{y}_{3}\right)+A_{33}\left(y_{3}-\bar{y}_{3}\right)^{2}\right\}\right],
\end{aligned}
$$

where $\bar{y}_{1}, \bar{y}_{2}, \bar{y}_{3}$ are the mathematical expectations of the regulated coordinates, which for the considered object are given by values of the arc currents according to the phases of an arc furnace; $A_{i, j}=A_{j, i}$ 
since the matrix of correlation $\Lambda_{y}$ between the components of the elements of the three-dimensional vector is symmetric.

Using (4), we obtain:

$$
\begin{gathered}
\ln p\left(y_{1}, y_{2}, y_{3}\right)=\ln \frac{1}{(2 \pi)^{3 / 2} \sqrt{\operatorname{det} \Lambda_{y}}}-\frac{1}{2} \cdot \frac{1}{\operatorname{det} \Lambda_{y}} \cdot\left\{A_{11}\left(y_{1}-\bar{y}_{1}\right)^{2}+2 A_{12}\left(y_{1}-\bar{y}_{1}\right) \cdot\left(y_{2}-\bar{y}_{2}\right)\right. \\
\left.+2 A_{13}\left(y_{1}-\bar{y}_{1}\right) \cdot\left(y_{3}-\bar{y}_{3}\right)+A_{22}\left(y_{2}-\bar{y}_{2}\right)^{2}+2 A_{32}\left(y_{2}-\bar{y}_{2}\right) \cdot\left(y_{3}-\bar{y}_{3}\right)+A_{33}\left(y_{3}-\bar{y}_{3}\right)^{2}\right\} \\
\frac{\partial \ln p\left(y_{1}, y_{2}, y_{3}\right)}{\partial y_{1}}=-\frac{1}{\operatorname{det} \Lambda_{y}} \cdot\left[A_{11}\left(y_{1}-\bar{y}_{1}\right)+A_{12}\left(y_{2}-\bar{y}_{2}\right)+A_{13}\left(y_{3}-\bar{y}_{3}\right)\right] \\
\frac{\partial \ln p\left(y_{1}, y_{2}, y_{3}\right)}{\partial y_{2}}=-\frac{1}{\operatorname{det} \Lambda_{y}} \cdot\left[A_{12}\left(y_{1}-\bar{y}_{1}\right)+A_{22}\left(y_{2}-\bar{y}_{2}\right)+A_{32}\left(y_{3}-\bar{y}_{3}\right)\right] \\
\frac{\partial \ln p\left(y_{1}, y_{2}, y_{3}\right)}{\partial y_{3}}=-\frac{1}{\operatorname{det} \Lambda_{y}} \cdot\left[A_{13}\left(y_{1}-\bar{y}_{1}\right)+A_{32}\left(y_{2}-\bar{y}_{2}\right)+A_{33}\left(y_{3}-\bar{y}_{3}\right)\right]
\end{gathered}
$$

If in Eqs. (5), instead of generalized regulated coordinates $y_{i}$, substitute the phase currents (arcs) $I_{A}, I_{B}, I_{C}$ and instead of $\Lambda_{y}$ substitute the correlation matrix $\Lambda_{I}$ of the three-dimensional vector of the arc currents, we obtain the expressions for the above-mentioned controlling influences $u_{A}, u_{B}, u_{C}$ for each of the phases of the arc furnace in the following form:

$$
\begin{aligned}
& u_{A}=d_{1} \cdot \operatorname{sign}\left\{-\frac{1}{\operatorname{det} \Lambda_{I}} \cdot\left[A_{11}\left(I_{A}-\bar{I}_{A}\right)+A_{12}\left(I_{B}-\bar{I}_{B}\right)+A_{13}\left(I_{C}-\bar{I}_{C}\right)\right]\right\} \\
& u_{B}=d_{1} \cdot \operatorname{sign}\left\{-\frac{1}{\operatorname{det} \Lambda_{I}} \cdot\left[A_{21}\left(I_{A}-\bar{I}_{A}\right)+A_{22}\left(I_{B}-\bar{I}_{B}\right)+A_{23}\left(I_{C}-\bar{I}_{C}\right)\right]\right\} \\
& u_{C}=d_{1} \cdot \operatorname{sign}\left\{-\frac{1}{\operatorname{det} \Lambda_{I}} \cdot\left[A_{31}\left(I_{A}-\bar{I}_{A}\right)+A_{32}\left(I_{B}-\bar{I}_{B}\right)+A_{33}\left(I_{C}-\bar{I}_{C}\right)\right]\right\} .
\end{aligned}
$$

Here we note that the control signals for the obtained Eqs. (5) are formulated as boundary controls and they can be considered only as conditionally optimal. However, in [8] the investigations are shown that these controls can be quite close, and even coincide with the strictly optimal controls that transfer the $n$-dimensional distribution into a normal distribution with a minimal dispersion of the three-dimensional vector.

It should be also noted that for the case of controlling the electric mode of an arc furnace using the known two-circuit system [9-11], this conclusion is completely substantiated, because the dynamics of the high-speed circuit is extremely close to the non-inertial one.

\section{The optimal control synthesis algorithm}

The computational procedure for the developed in this paper mathematical model of control synthesis on the basis of the three-dimensional vector of phase currents is reproduced by the shown in Fig. 1 algorithm.

At the start of the algorithm (block 2), there are inputted the arc furnace phase currents $\bar{I}_{A}, \bar{I}_{B}$, $\bar{I}_{C}$, the value of the change discrete of the controlling influence $d$, the time interval $\Delta t$ of the calculation of the current true value of the phase currents, the value $N$, which specifies the length of the stationary interval of the phase currents change processes, $A_{i, j}$ are the elements of the adjoint matrix, and the determinant $\operatorname{det} \Lambda_{I}$ of the correlation matrix $\Lambda_{I}$ of the three-dimensional vector of the arc currents. 
The presented algorithm contains three cycles. In the first internal cycle (blocks 5, 6, 7), on each computation interval (for example, over the voltage period $\Delta t=0.02 \mathrm{~s}$ ) the current values of phase currents $I_{A}, I_{B}, I_{C}$ are found.

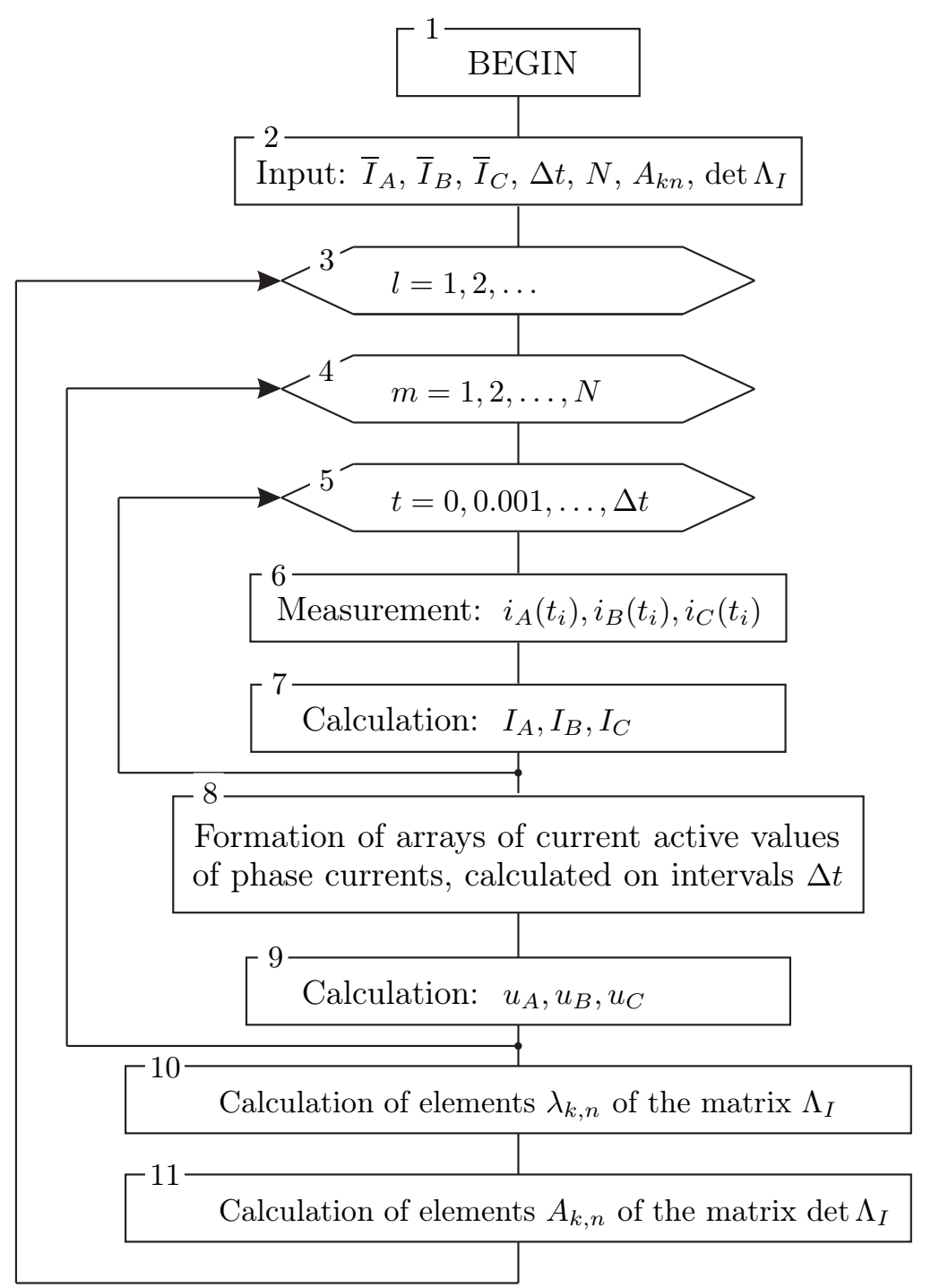

Fig. 1. Algorithm for synthesis of optimal control of electric mode according to the criterion of minimization of dispersion of three-dimensional vector of phase currents.

The second inner cycle includes the blocks 5, 6, 7 and the blocks 8 and 9. This cycle is performed $N$ times on each $m$-th interval of the stationary processes of the furnace arc current changes: $N=$ $T_{c} / \Delta t$, where $T_{c}$ is the duration of stationary interval. For different arc furnaces and technological smelting stages $T_{c}=100-200 \mathrm{~s}$. This loop is designed to form the arrays of current active values of phase currents $A, B$, or $C$, respectively, in the block 8 on each $m$-th stationary interval. The time dependencies of changes in the values of the elements of these arrays reflect the stochastic properties of the processes of change of the phase currents on the current stationary interval. In the last block 9 of this cycle, taking into account the current active values of phase currents $I_{A}, I_{B}, I_{C}$, the calculation of the controlling influences $u_{A}, u_{B}, u_{C}$ of each phase of the control system of the arc furnace electric mode is performed on the basis of the obtained mathematical model (5).

At the end of each $m$-th stationary interval, the function performances of the blocks 10 and 11 of the third outer loop are initialized. In these blocks, adaptation of the parameters of the obtained above 
mathematical model (5) of the synthesis of optimal control of the electric mode is conducted according to the criterion of the minimum of dispersion of the three-dimensional vector of the phases currents of an arc furnace to the change in the parameters of stochastic characteristics of the processes of the change of the phase currents. For this to be done, in the block 10, the elements $\lambda_{k, n}$ of the correlation matrix $\Lambda_{I}$ of three-dimensional vector of the arc currents (matrix of second moments) are calculated

$$
\Lambda_{I}=\left|\begin{array}{lll}
\lambda_{A A} & \lambda_{A B} & \lambda_{A C} \\
\lambda_{B A} & \lambda_{B B} & \lambda_{B A} \\
\lambda_{C A} & \lambda_{C B} & \lambda_{C C}
\end{array}\right|,
$$

where $\lambda_{k n}=\lambda_{n k}=M\left[\left(I_{k}-\bar{I}_{k}\right)\left(I_{n}-\bar{I}_{n}\right)\right], k=A, B, C ; n=A, B, C$.

The values of the main diagonal $(k=n)$ of the resulting matrix $\Lambda_{I}$ are equal to the dispersion $\lambda_{A A}=D_{I_{A}}, \lambda_{B B}=D_{I_{B}}, \lambda_{C C}=D_{I_{C}}$ of the current of the corresponding phase, and the values of the elements for which $k \neq n$ correspond to the values of the second mixed central moment. In the block 11 of the external cycle, the determinant $\operatorname{det} \Lambda_{I}$ is calculated, as well as the elements $A_{k n}$ of the adjoint matrix of the inverse matrix $\Lambda_{I}^{-1}$.

Using in the block 9 the parameters of the model of the synthesis of control signals (4) $A_{k n}$ and $\operatorname{det} \Lambda_{I}$, operatively updated on each stationary interval, allows us to implement the adaptation of the process of optimal control of the electric mode to the change of the stochastic characteristics of the processes of change of the phase currents.

As we see, for the operative formation (computation) of the necessary controlling influences it is necessary to know the matrix $\Lambda_{I}$ of the second moments of the three-dimensional vector of currents of arcs (phases) of an arc furnace. The operative calculation of the controlling influences according to the obtained model (4) for modern microprocessor devices is a simple (to some extent trivial) technical problem, according to which on the basis of the values of realization of the half-period average currents of three phases $I_{A}, I_{B}, I_{C}$ of an arc furnace, the calculation of the matrix $\Lambda_{I}$ of the second moments of the three-dimensional vector of the currents of the arcs of an arc furnace, of its determinant det $\Lambda_{I}$, as well as of the elements $A_{k n}$ of the adjoint matrix of the inverse matrix $\Lambda_{I}^{-1}$ is carried out are operatively on each stationary interval $(T=100-200 \mathrm{~s})$ of the processes of change of the phases currents of an electric arc furnace.

Due to the fact that the model (4) uses the correlation matrix $\Lambda_{I}$ of the second moments of the three-dimensional vector of arc currents of an arc furnace, being operatively computed on each time interval of stationary $T=100-200 \mathrm{~s}$, the adaptation of the control to the change in the parameters of the stochastic characteristics of the phase currents determined by stochastic characteristics of the coordinate and parametric disturbances is automatically implemented, as has already been said, in the course of changing the technological smelting stages. This enables to implement the adaptive optimal control over the full smelting period according to the criterion of minimizing the dispersion of the three-dimensional vector of the arc currents of an arc furnace.

Thus, due to the model of operative formation and adaptation of the vector of controlling influences obtained in the work and its realization through the adaptive arc current control circuit [10] for the formation of the dispersion of the three-dimensional vector of the arc currents of an arc furnace, we can obtain a significant approximation of the distribution of the three-dimensional vector of the phases currents of an arc furnace to the normal distribution with dispersion, which tends to zero. And the fact that the reduction of the dispersion of the arc currents substantially affects the improvement of the indicators of energy efficiency (electrical efficiency of the furnace, specific energy consumption, specific capacity of an EAF, the price of the ton of smelted steel, etc.) of such an electrotechnical installation, which the electric arc furnace of an alternating current is, has been shown in the studies of many domestic and foreign scholars.

It should be also noted that the suggested method for the adjustment of the coordinates of the electric mode of an EAF and the model of adaptive synthesis of control signals based on the three- 
dimensional vector of the phase currents implements the relay law (in contrast to the existing) of regulation. Such a control law complied the stability, as it is known, provides the maximal rate of regulation response and, as a result, high dynamic accuracy of the arc currents stabilization at the level of optimal values for the chosen criterion, and it also is characterized by a significantly lower sensitivity to the change in the parameters of the control object, i.e. the three-phase arc parameter and the power circle (short grid) of an EAF. The last specificity of the proposed method is especially important for the implementation of strategies of adaptive optimal control in the conditions of continuous action of intense parametric perturbations in the power circle and in the arcs' intervals of an EAF during smelting.

The computing implementation of the obtained adaptive algorithm for operative synthesis of the control signal is done on the R7FS7G27H3A01CFC-type microcontroller (Renesas) and has the following main technical characteristics: Cortex-M4 Core, 240MHz Clock Rate, 4MB CodeFlash, 126 Inputs/Outputs, 12-bit DAC/ADC.

\section{Conclusion}

The article deals with the theoretical bases of the method of controlling the electric mode of an electric arc smelting furnace on the basis of a three-dimensional vector of phase currents (three-phase arcs), which makes it possible to implement an adaptive optimal strategy of the control of electric mode according to the criterion of the minimum dispersion of the arc currents.

[1] Lozynskyi O., Maruschak Ya. Three-dimensional stochastic model of the electric mode regulation of an arc furnace. Automation of production processes in mechanical engineering and instrumentation. 31, 7-11 (1993).

[2] Lozynskyi O., Parancuk Ya., Lozynskyi A. Optimization of dynamic regimes of interconnected electromechanical systems. Visnyk of Lviv Polytechnic National University: "Electrical and electromechanical systems". 421, 98-103 (2001).

[3] Nikolaev A., Povelitsa E., Kornilov G., Anufriev A. Research and Development of Automatic Control System for Electric Arc Furnace Electrode Positioning. Appl. Mech. Mater. 785, 707-713 (2015).

[4] Ghiormez L., Pănoiu M. Curent control of a 3-phase electric arc furnace using fuzzy logic. ANNALS of Faculty Engineering Hunedoara. Inter. J. Engineering. XIII (4), 237-242 (2015).

[5] Nikolaev A. A., Tulupov P. G. Method of setting optimum asymmetric mode of operation of electric arc furnace. 2016 11th France-Japan \& 9th Europe-Asia Congress on Mechatronics (MECATRONICS) 17th International Conference on Research and Education in Mechatronics (REM), Compiegne. 033-037 (2016).

[6] Zheng T., Makram E. B. An Adaptive Arc Furnace Model. IEEE Transaction on power delivery. 15 (3), 931-939 (2000).

[7] Rahmatollah Hooshmand, Mahdi Banejad, Mahdi Torabian Esfahani. A New Time Domain Model for Electric Arc Furnace. Journal of Electrical Engineering. 59 (4), 195-202 (2008).

[8] Krasovsky A. A. Statistical theory of transients in control systems. Moscow, Nauka (1968), (in Russian).

[9] Lozynskyi O., Paranchuk Y., Stakhiv P. The study of dynamics of the two-loop arc furnace electric mode ACS on a Simulink-model. Przeglad Elektrotechniczny. 94 (12), 24-27 (2018).

[10] Lozynskyy O., Lozynskyy A., Paranchuk Y., Paranchuk R., Marushchak Y., Malyar A. Analysis and synthesis of intelligent system for electric mode control in electric arc furnace. Lecture Notes in Electrical Engineering. 452, 111-130 (2018).

[11] Lozynskyi O., Lozynskyi A., Paranchuk Y., Paranchuk R., Holovach I., Tsyapa V. Fuzzy extreme control and electric mode coordinates stabilization of arc steel-melting furnace. 2016 XIth International Scientific and Technical Conference Computer Sciences and Information Technologies (CSIT). 49-54 (2016). 


\section{Оптимальне керування електричним режимом дугової печі на основі тривимірного вектора струмів дуг}

Лозинський О., Лозинський А., Паранчук Я., Білецький Ю.

Національний університет “Лъвівсъка політехніка", вул. С. Бандери, 12, Львів, 79013, Україна

У роботі на основі рівняння Фоккера-Планка-Колмогорова та статистичної теорії керування отримано математичну модель оперативного синтезу оптимальних керуючих впливів для стабілізації електричного режиму дугової сталеплавильної печі в двоконтурній структурі з швидкодіючим електричним контуром регулювання струмів дуг.

Ключові слова: дугова сталеплавильна піч, електричний режсим, трифазний вектор струмів фаз, дельта-функиія, дисперсія, оптимізація, адаптація.

2000 MSC: $93 \mathrm{E} 20$

удк: $681.513,621.365,62-83-52$ 